\title{
SUMMARY OF NATURAL DISASTER RESPONSES BY THE ADVANCED LAND OBSERVING SATELLITE-2 (ALOS-2)
}

\author{
T. Tadono ${ }^{1, *}$, M. Ohki $^{1}$, T. Abe ${ }^{1}$ \\ ${ }^{1}$ Earth Observation Research Center, Japan Aerospace Exploration Agency (JAXA), 2-1-1 Sengen, Tsukuba, Ibaraki, Japan \\ - (tadono.takeo, ohki.masato, abe.takahiro2)@jaxa.jp
}

Commission III, WG III/2

KEY WORDS: SAR, L-band, PALSAR-2, disaster analysis, change detection

\begin{abstract}
:
The Advanced Land Observing Satellite-2 (ALOS-2) was launched on May 24, 2014, and it is operating very well in space more than 4.5 years. The designed mission life is five years as nominal operational phase and the target is over seven years since launch the satellite. The mission objectives of ALOS-2 are 1) disaster monitoring, 2) national land and infrastructure information, 3) cultivated area monitoring, and 4) global forest monitoring. To achieve the objectives, ALOS-2 carries on the Phased Array type Lband Synthetic Aperture Radar-2 (PALSAR-2), which is an active microwave radar using the $1.2 \mathrm{GHz}$ frequency band and observes in day and night times even in bad weather conditions as successor PALSAR instrument onboard ALOS satellite operated from 2006 to 2011. PALSAR-2 instrument has several enhanced features from PALSAR e.g. finer spatial resolution, spotlight observing mode, dual-polarisation ScanSAR. This paper summarises an introduction of typical data analysis results for monitoring natural disasters by ALOS-2 during the operational phase. As the response natural disasters, more than 400 times of the emergency observations have been conducted to identify damages caused by volcanic activities, earthquakes, flooding etc. happened in Japan and the World.
\end{abstract}

\section{INTRODUCTION}

Anyone don't know that when and where does a natural disaster happen, however it causes sometime serious damages to human activities and life if it was occurred. When a disaster happens, disaster response agencies would collect information for assessing damages and planning rescue activities as soon as possible. An Earth observation satellite plays an important role in collecting the information. The Advanced Land Observing Satellite-2 (ALOS-2) was launched on May 24, 2014, and it is currently operating very well more than 4.5 years. One of the mission objectives of ALOS-2 is a disaster monitoring of damage areas both in considerable detail and when these areas may be large. The Phased Array type L-band Synthetic Aperture Radar-2 (PALSAR-2) is an active microwave radar instrument and carry on ALOS-2 to contribute the mission objective.

This paper describes examples of data analysis results by ALOS-2 for monitoring natural disasters during the operational phase. As the response natural disasters, more than 400 times of the emergency observations have been conducted to identify damages caused by volcanic activities, earthquakes, flooding etc. occurred in not only Japan but also the World.

\section{ALOS-2 AND PALSAR-2 SPECIFICATIONS}

Figure 1 shows an in-orbit configuration of ALOS-2, and Table 1 summarizes its specifications (Arikawa et al., 2014). ALOS-2 is a synthetic aperture radar (SAR) mission as a successor PALSAR onboard ALOS satellite that operated from 2006 to 2011 (Shimada et al., 2010). SAR can observe the Earth surface in day- and night-time even under bad weather conditions that effective for monitoring disaster. To share the emergency observations with other satellites effectively, ALOS-2 takes

\footnotetext{
* Corresponding author
}

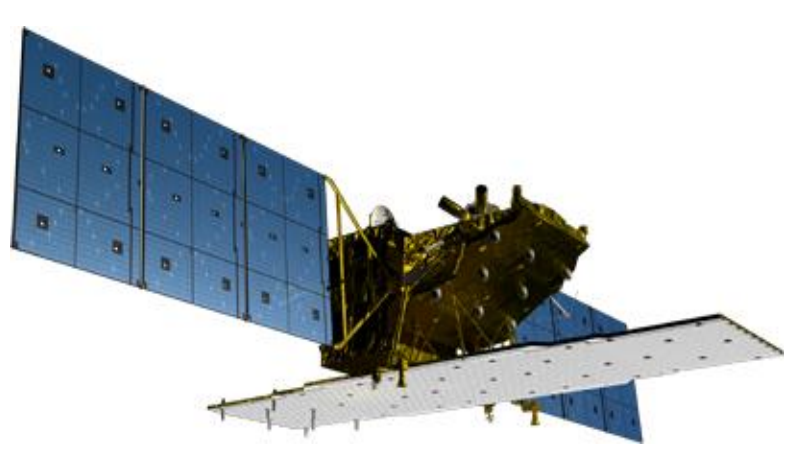

Figure 1. ALOS-2 in-orbit configuration

Table 1. ALOS-2 specifications

\begin{tabular}{|c|c|c|}
\hline \multicolumn{2}{|l|}{ Items } & Specifications \\
\hline \multirow[t]{5}{*}{ Orbit } & Type & Sun-synchronous sub-recurrent \\
\hline & Altitude & $628 \mathrm{~km}$ at the equator \\
\hline & LST & $12: 00+/-15$ mins \\
\hline & Revisit & 14 days \\
\hline & Control & $<+/-500 \mathrm{~m}$ \\
\hline \multicolumn{2}{|l|}{ Size } & $3.7 \mathrm{~m} \mathrm{x} 16.5 \mathrm{~m} \mathrm{x} 10.0 \mathrm{~m}$ in-orbit \\
\hline \multicolumn{2}{|c|}{ Mass } & Approx. 2 tons at launch \\
\hline \multicolumn{2}{|c|}{ Design Life time } & Over 5 years (target: 7 years) \\
\hline \multicolumn{2}{|c|}{$\begin{array}{l}\text { Mission data } \\
\text { Downlink }\end{array}$} & $\begin{array}{c}\text { X-band: } 800 \text { Mbps (16QAM), } \\
\text { 400/200 Mbps (QPSK) } \\
\text { Ka-band: } 278 \text { Mbps (QPSK) via. DRTS }\end{array}$ \\
\hline \multicolumn{2}{|c|}{ Instrument } & $\begin{array}{l}\text { Phased Array type L-band Synthetic } \\
\text { Aperture Radar-2 (PALSAR-2) }\end{array}$ \\
\hline
\end{tabular}


Table 2. PALSAR-2 observation modes and characteristics

\begin{tabular}{|c|c|c|c|c|c|c|c|c|}
\hline \multirow{2}{*}{\multicolumn{2}{|c|}{ Bandwidth }} & \multirow{2}{*}{$\begin{array}{c}\text { Spotlight } \\
84 \mathrm{MHz}\end{array}$} & \multirow{2}{*}{$\begin{array}{c}\text { Ultra Fine } \\
84 \mathrm{MHz}\end{array}$} & \multirow{2}{*}{$\begin{array}{c}\begin{array}{c}\text { High } \\
\text { sensitive }\end{array} \\
42 \mathrm{MHz}\end{array}$} & \multirow{2}{*}{$\begin{array}{l}\text { Fine } \\
28 \mathrm{MHz}\end{array}$} & \multicolumn{2}{|c|}{$\begin{array}{l}\text { ScanSAR } \\
\text { nominal }\end{array}$} & \multirow{2}{*}{$\begin{array}{c}\begin{array}{c}\text { ScanSAR } \\
\text { wide }\end{array} \\
14 \mathrm{MHz}\end{array}$} \\
\hline & & & & & & $14 \mathrm{MHz}$ & $28 \mathrm{MHz}$ & \\
\hline \multicolumn{2}{|c|}{ Resolution } & $\begin{array}{l}\mathrm{Rg} \times \mathrm{Az}: \\
3 \times 1 \mathrm{~m}\end{array}$ & $3 m$ & $6 m$ & $10 \mathrm{~m}$ & \multicolumn{2}{|c|}{$\begin{array}{c}100 \mathrm{~m} \\
\text { (multilook) }\end{array}$} & $\begin{array}{c}60 \mathrm{~m} \\
\text { (multilook) }\end{array}$ \\
\hline \multicolumn{2}{|c|}{ Swath } & $\begin{array}{c}\mathrm{Rg} \times \mathrm{Az}: \\
25 \times 25 \mathrm{~km}\end{array}$ & $50 \mathrm{~km}$ & $50 \mathrm{~km}$ & $70 \mathrm{~km}$ & \multicolumn{2}{|c|}{$\begin{array}{c}350 \mathrm{~km} \\
\text { (5-scan) }\end{array}$} & $\begin{array}{c}490 \mathrm{~km} \\
\text { (7-scan) }\end{array}$ \\
\hline \multicolumn{2}{|c|}{ Polarization } & SP & SP/DP & \multicolumn{2}{|c|}{ SP/DP/QP/CP } & \multicolumn{3}{|c|}{ SP/DP } \\
\hline \multicolumn{2}{|c|}{ NESZ } & $-24 \mathrm{~dB}$ & $-24 \mathrm{~dB}$ & $-28 \mathrm{~dB}$ & $-26 \mathrm{~dB}$ & $-26 \mathrm{~dB}$ & $-23 \mathrm{~dB}$ & $-23 \mathrm{~dB}$ \\
\hline \multirow{2}{*}{ S/A } & $\mathbf{R g}$ & $25 \mathrm{~dB}$ & $25 \mathrm{~dB}$ & $23 \mathrm{~dB}$ & $25 \mathrm{~dB}$ & \multicolumn{2}{|c|}{$25 \mathrm{~dB}$} & $20 \mathrm{~dB}$ \\
\hline & Az & $20 \mathrm{~dB}$ & $25 \mathrm{~dB}$ & $20 \mathrm{~dB}$ & $23 \mathrm{~dB}$ & \multicolumn{2}{|c|}{$20 \mathrm{~dB}$} & $20 \mathrm{~dB}$ \\
\hline
\end{tabular}

SP: $\mathrm{HH}$ or VV or HV, DP: $\mathrm{HH}+\mathrm{HV}$ or VV+VH,

QP: $\mathrm{HH}+\mathrm{HV}+\mathrm{VH}+\mathrm{VV}, \mathrm{CP}:$ Compact Pol (Experimental)

12:00 of the local sun time (LST), and 14 days of revisit.

Table 2 summarizes PALSAR-2 observation modes and corresponding characteristics (Kankaku et al., 2013). PALSAR2 provides three major observing modes i.e. 1) Spotlight with $3 \times 1 \mathrm{~m}$ resolution and $25 \mathrm{~km}$ swath width, 2) Stripmap with $3 \mathrm{~m}$ (Ultra-Fine), $6 \mathrm{~m}$ (High-sensitive), and $10 \mathrm{~m}$ (Fine), and 50 to $70 \mathrm{~km}$ swath, and 3) ScanSAR with $100 / 60 \mathrm{~m}$ resolution and $350 / 490 \mathrm{~km}$ swath. Each mode has different polarizations i.e. single polarization (SP), dual-pol (DP), and quad-pol (QP). Compact polarimetry (CP) is provided in Stripmap observation mode as experimental purpose. Note that PALSAR-2 can observe both right- and left-looking, and the incidence angle changes from $8 \mathrm{deg}$. of near-range to $70 \mathrm{deg}$. of far-range to cover wide observing swath width. This wide coverage is basically important for emergency observation to collect the information as soon as after occurring an event, however analysis of the data acquired by different incidence angles are significantly difficult. An initial operation result of ALOS-2 and PALSAR-2 was summarised by Kankaku et al. (2015).

\section{EXAMPLES OF DISASTER RESPONSES}

Regarding to analyse data by ALOS-2 in disaster responses, it is basically applied the change detection and SAR Interferometry (InSAR) techniques using acquired before and after the event. Therefore, the updating archived data are essential by corresponding observation mode as pre-event data. This is achieved by the "Basic Observation Scenario" (BOS) in ALOS2 , which is a systematic observation strategy and scheduled adequate planning without or minimise conflicts of user requests (Kankaku et al., 2016).

Many large disasters occurred in 2018 in Japan as well as the World. In this section, some typical examples of data analyses using ALOS-2 are introduced.

\subsection{Eruption of Mt. Kilauea and Earthquake in Hawaii}

Mt. Kilauea in Big Island, Hawaii, US has been erupting since May 3, 2018, and a major earthquake of Mw 6.9 occurred close to Mt. Kilauea on May 4, 2018. Based on the data acquisition request from Jet Propulsion Laboratory (JPL) and United States Geological Survey (USGS), the Japan Aerospace Exploration Agency (JAXA) performed a series of emergency observations by ALOS-2 from May 8, 2018. Since then, intensive emergency observations continuously conducted by several observation modes of ALOS-2 until November 2018.

Figure 2 shows the ScanSAR InSAR interferogram using PALSAR-2 acquired on Jan. 20, 2018 and May 12, 2018. The wider crustal deformation has been revealed. The image shows $\sim 100 \mathrm{~cm}$ displacement toward the satellite in south part from Leilani Estates. Moreover, $\sim 50 \mathrm{~cm}$ displacement away from satellite was detected around Halemaumau Crater. Figure 3 shows comparisons of amplitude images around Halemaumau

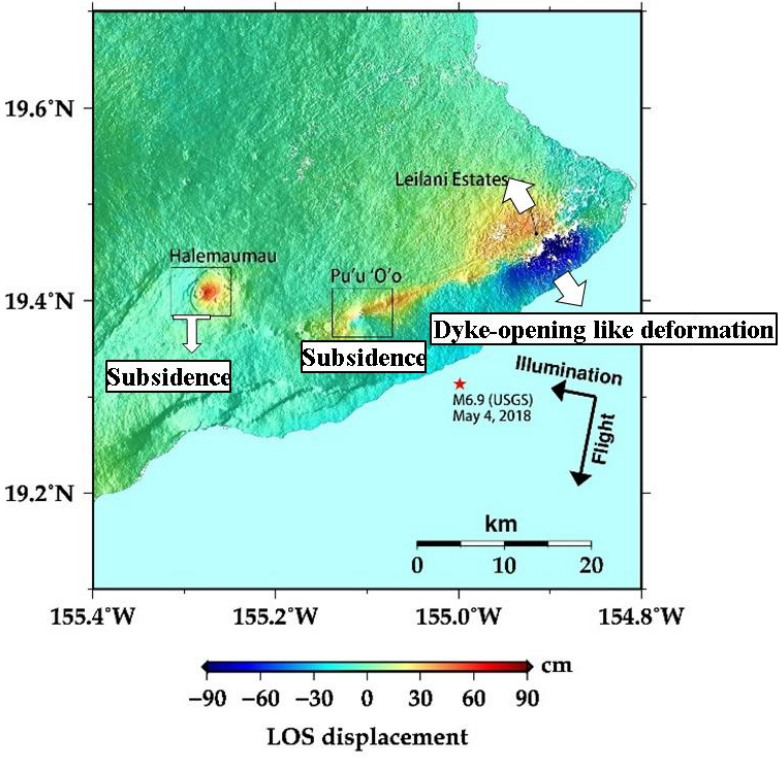

Figure 2. An interferometric image of the PALSAR-2 ScanSAR data acquired before (January 20, 2018) and after (May 12, 2018) the eruption and earthquake
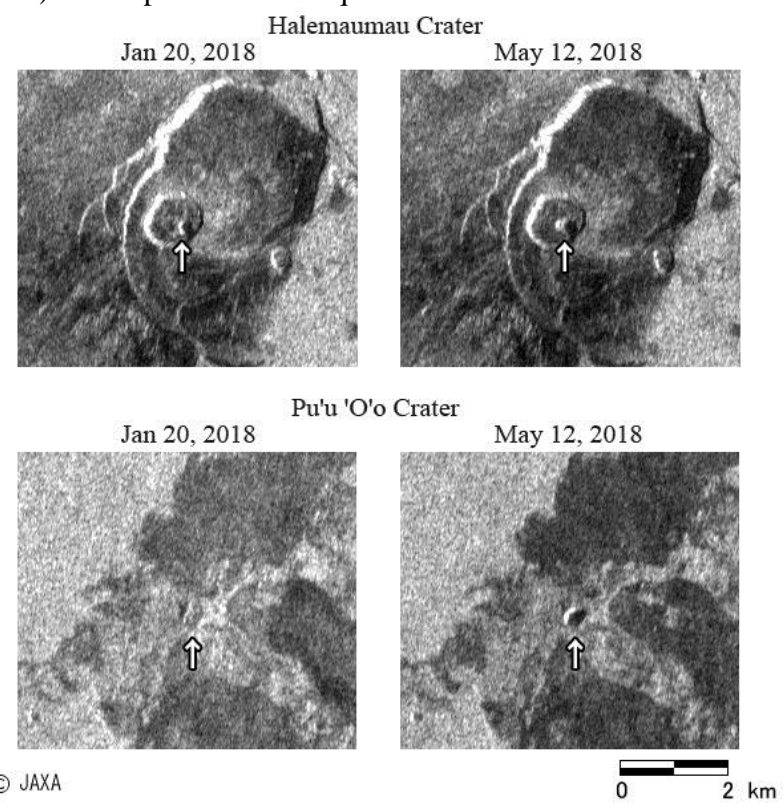

Figure 3. Comparison of the two $\mathrm{HH}$ amplitude images acquired before (Jan. 20, 2018) and after (May 12, 2018) the eruption

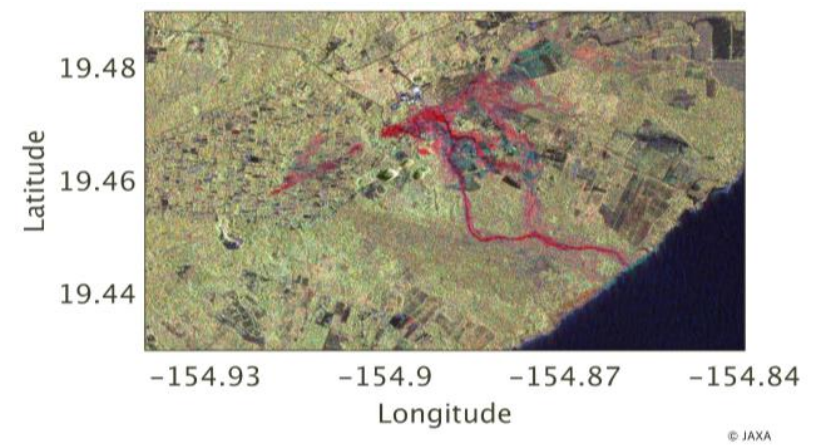

Figure 4. Color-composite image using Stripmap data acquired before (Feb. 27, 2018) and after (May 22, 2018) assigned as R, $\mathrm{G}, \mathrm{B}=\mathrm{HV} \_$bef, HV_aft, HH_aft. As the result, lava flows were shown in red color. 


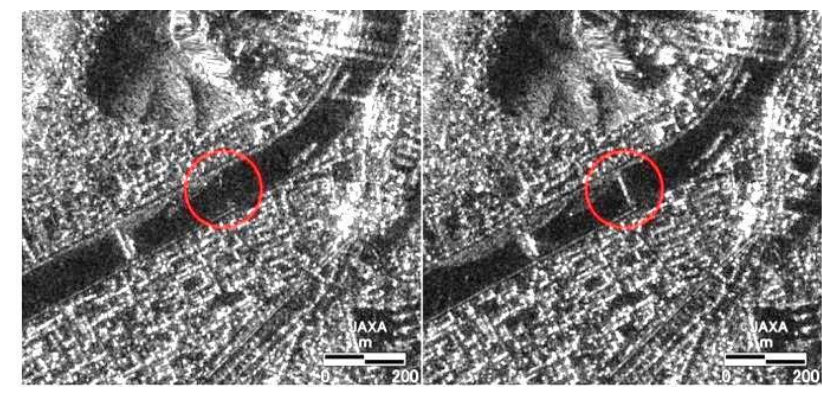

Figure 5. The loss of bridge in Kure City, Hiroshima Pref., Japan from comparison of the two $\mathrm{HH}$ amplitude images acquired after (July 8, 2018, left) and before (Apr. 19, 2015, right) due to heavy rain.
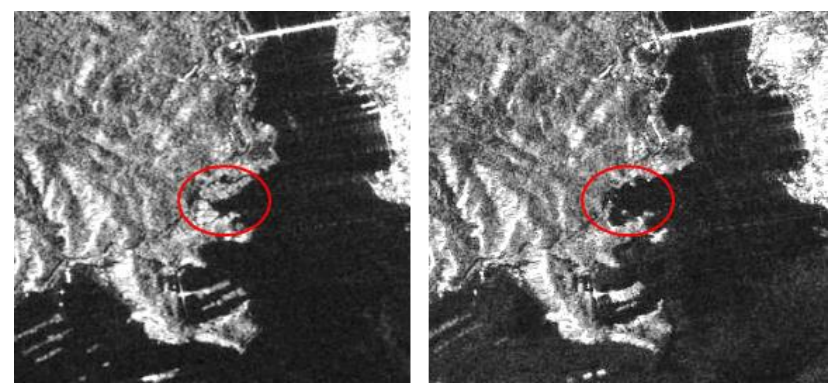

Figure 6. The driftwoods in bay of Hiroshima Pref., Japan from comparison of the two $\mathrm{HH}$ amplitude images acquired after (July 21, 2018, left) and before (Apr. 19, 2015, right) due to heavy rain.

crater (upper) and Pu'u 'O'o crater (lower) on May 12 and Jan. 20,2018 . In both craters, terrain inside the craters has changed due to the lowered lava lake level. Figure 4 shows a colorcomposite image (red: HV polarization on Feb. 27, 2018, green: HV on May 22, 2018, blue: HH on May 22, 2018) around Leilani Estates where eruptive fissures and lava flows can be seen in red color.

These results and information have been shared with JPL, USGS, and USGS Hawaiian Volcano Observatory as soon as after the analysis, and probably used for rescuing activities.

\subsection{July heavy rain in western Japan}

Based on requests from the Ministry of Land, Infrastructure and Transport (MLIT), Japan, emergency observations by ALOS-2 conducted to identify damaged areas as well as flooding caused by recordable heavy rain mainly in western Japan due to the influence of Typhoon No. 7 in July 2018.

Figures 5 and 6 show damage areas extractions i.e. a bridge loss and driftwoods in the bay in Hiroshima Pref., Japan, by comparing two $\mathrm{HH}$ polarization images acquired before and after the event. These images acquired by Stripmap Ultra-Fine mode ( $3 \mathrm{~m}$ spatial resolution). Figure 7 shows the expected flooding areas (colored by cyan) in Okayama Pref., Japan using PALSAR-2 acquired after (July 8, 2018) and before (multitemporal images). The water surface has basically low brightness into SAR amplitude image, however it may contain not only flooding by heavy rain but also seasonal changes of paddy fields etc. To reduce such seasonal change effects and noises in SAR image, multi-temporal images were used here as before the event, which was calculated darker pixels from image acquired same season before (July 2016) and just before the event (Apr. 2018).

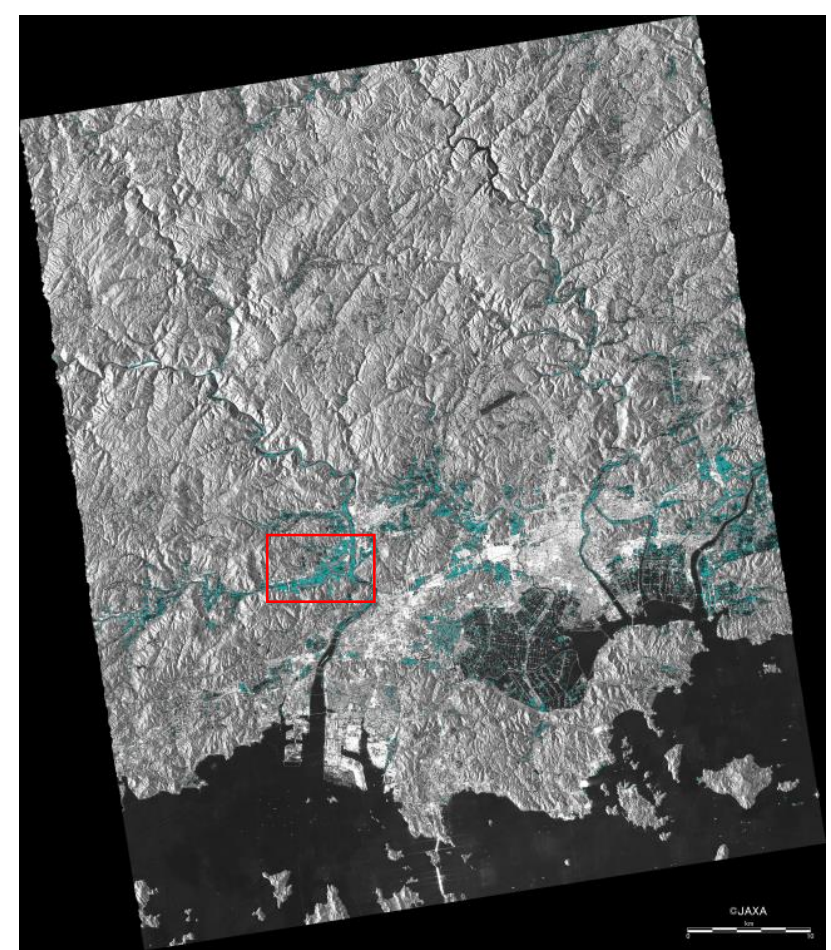

(a) The expected flooding around Okayama Pref., Japan

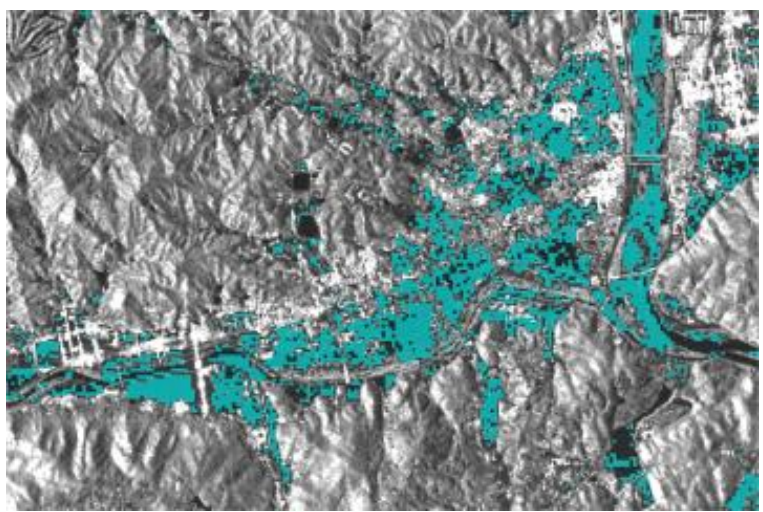

(b) Enlarged image in red square of (a)

Figure 7. The expected flooding areas in Okayama Pref., Japan estimated by PALSAR-2 images acquired after (July 8, 2018) and before (multi-temporal images) colored by cyan.

\subsection{Hokkaido Iburi-Toubu earthquake in 2018}

A major earthquake of Mw 6.6 occurred in Iburi province, eastern Hokkaido, which is located near Sapporo, Chitose, and Tomakomai Cities at 3:07am on Sep. 6, 2018 (Japan Standard Time) that was caused many landslides in wide ranges of surrounding mountainous areas. Based on the requests from MLIT, Japan, emergency observations by ALOS-2 conducted to identify damaged areas estimation from 11:41am on Sep. 6, 2018.

Figure 8 shows a color-composite image (red: HH on Aug. 23, 2018, green and blue: HH on Sep. 6, 2018) around Iburi province, eastern Hokkaido. In general, forest area has brighter pixel in SAR image, and bare surface darker. Therefore, changing pixels from brighter to darker in forest areas may expect to landslide sites in image acquired before and after the event. As the results, estimated damaged areas by landslides (colored by red) as well as debris areas caused by them (colored by cyan) in Figure 8 . These images were acquired by ALOS-2 Stripmap Ultra-Fine mode and $3 \mathrm{~m}$ resolution. 


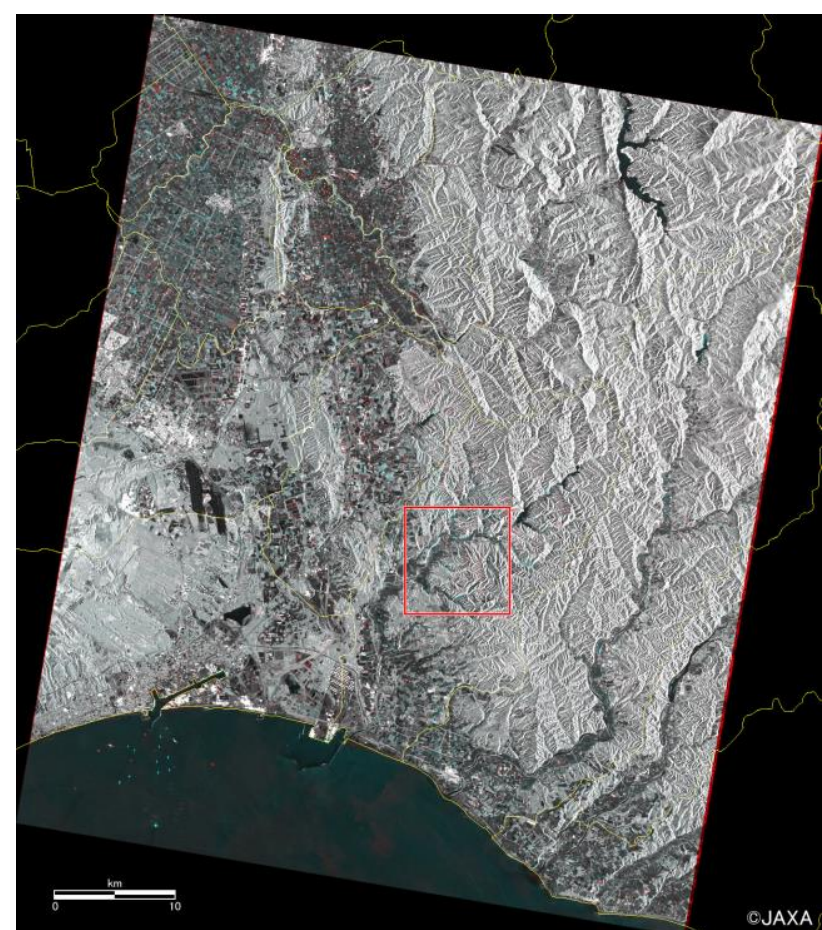

(a) The expected landslides around eastern Hokkaido, Japan

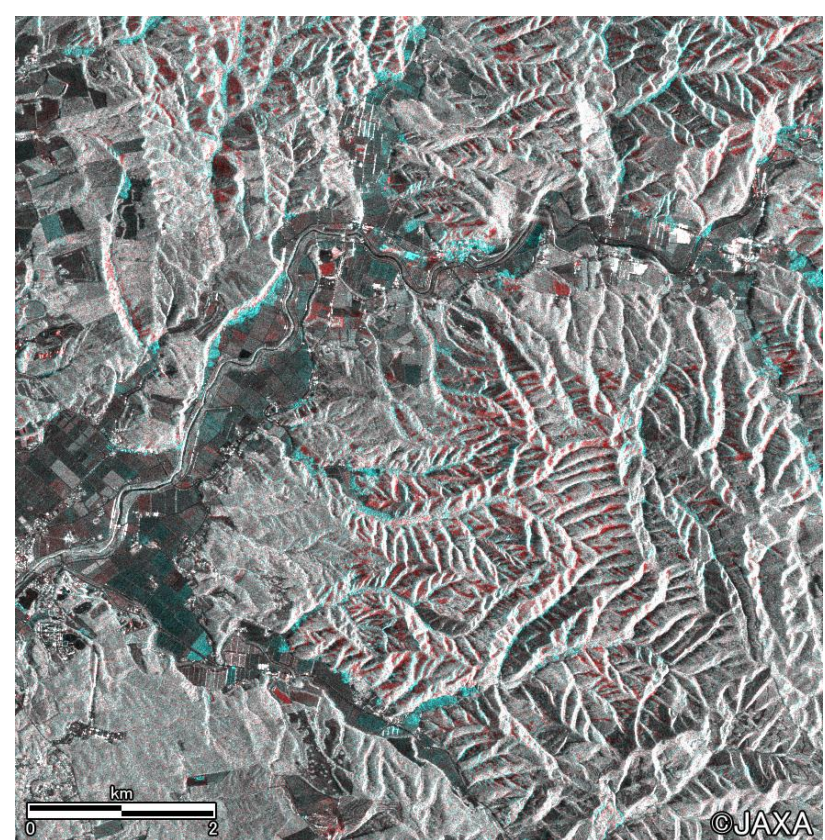

(b) Enlarged image in red square of (a)

Figure 8 . The expected landslides (colored by red) and debris areas (colored by cyan) in eastern Hokkaido, Japan estimated by PALSAR-2 images acquired after (Sep. 6, 2018) and before (Aug. 23, 2018) the earthquake.

\section{CONCLUSIONS}

Recently, Earth observation satellites become an essential tool for the quick responses in natural disaster monitoring. This paper introduced an overview of ALOS-2 and its mission, and examples of practical analysis results for monitoring natural disasters. ALOS-2 is almost completed the nominal operational phase by May 2019 and hopes to operate continuously as longer as possible. During the nominal operational phase, more than 400 times of the emergency observations have been conducted to identify damages caused by volcanic activities, earthquakes, flooding etc. occurred in not only Japan but also the World. The results showed that ALOS-2 has good performances in disaster responses such as all-time observation and high-coherences of L-band SAR, and fine-resolution and wide-swath width observation capabilities. Other examples of data analysis can be found on JAXA EORC (2019).

JAXA is currently under developing of ALOS-3 that is a successor ALOS optical mission with finer resolution and wide swath observation (Tadono et al., 2018), and ALOS-4 that is ALOS-2 follow on SAR mission (Okada et al., 2018). Both missions have an objective to contribute safe and secure social including natural disaster responses, and are planned to be launch around Japanese Fiscal Year 2020.

\section{REFERENCES}

Arikawa, Y., Saruwatari, H., Hatooka, Y., and Suzuki, S., 2014. ALOS-2 Launch and Early Orbit Operation Result. In: Proc. International Geoscience and Remote Sensing Symposium (IGARSS), IEEE, pp. 3406-3409.

JAXA EORC, 2019. ALOS-2 Research and Application Project, https://www.eorc.jaxa.jp/ALOS/en/index.htm (10 Jan. 2019).

Kankaku, Y., Suzuki, S., and Osawa, Y., 2013. ALOS-2 Mission and Development Status. In: Proc. International Geoscience and Remote Sensing Symposium (IGARSS), IEEE, pp. 2396-2399.

Kankaku, Y., Suzuki, S., and Shimada, M., 2015. ALOS-2 First Year Operation Result. In: Proc. International Geoscience and Remote Sensing Symposium (IGARSS), IEEE, pp. 4121-4124.

Kankaku, Y., Suzuki, S., Motohka, T., Ohki, M., Natsuaki, R., and Shimada, M., 2016. ALOS-2 Operation Status. In: Proc. International Geoscience and Remote Sensing Symposium (IGARSS), IEEE, pp. 3846-3848.

Okada, Y., Yokota, Y., Matsuki, M., Arii, M., and Nakamura, S., 2018. Hardware Performance of PALSAR-3 Onboard ALOS-4. In: Proc. International Geoscience and Remote Sensing Symposium (IGARSS), IEEE, pp. 4175-4176.

Shimada, M., T. Tadono, and A. Rosenqvist, 2010. Advanced Land Observing Satellite (ALOS) and Monitoring Global Environmental Change. Proc. the IEEE, 98(5), pp. 780-799.

Tadono, T., Oka, A., Watarai, H., Takaku, J., Ohgushi, F., and Doutsu, M., 2018. Image Simulations for the Advanced Optical Satellite (ALOS-3). In: Proc. International Geoscience and Remote Sensing Symposium (IGARSS), IEEE, pp. 7731-7734. 